\title{
Environmental Control and Control of the Environment: The Basis of Longevity in Bivalves
}

\author{
Doris Abele $^{\mathrm{a}}$ Eva Philipp ${ }^{\mathrm{b}}$ \\ a Department of Functional Ecology, Alfred Wegner Institute for Polar and Marine Research, Bremerhaven, and \\ ${ }^{\mathrm{b}}$ Institute of Clinical Molecular Biology, Christian Albrechts University Kiel, Kiel, Germany
}

\section{Key Words}

Arctica islandica $\cdot$ Metabolic rate depression - Shell water •

Sex switch · Hypoxia reoxygenation · Oxidative stress

\begin{abstract}
Longevity and ageing are two sides of a coin, leaving the question open as to which one is the cause and which one the effect. At the individual level, the physiological rate of ageing determines the length of life (= individual longevity, as long as death results from old age and not from disease or other impacts). Individual longevity depends on the direct influence of environmental conditions with respect to nutrition, and the possibility for and timing of reproduction, as well as on the energetic costs animals invest in behavioural and physiological stress defence. All these environmental effectors influence hormonal and cellular signalling pathways that modify the individual physiological condition, the reproductive strategy, and the rate of ageing. At the species level, longevity (= maximum lifespan) is the result of an evolutionary process and, thus, largely determined by the species' behavioural and physiological adaptations to its ecological niche. Specifically, reproductive and breeding strategies have to be optimized in relation to local environmental conditions in different habitats. As a result of adaptive and
\end{abstract}

evolutionary processes, species longevity is genetically underpinned, not necessarily by a few ageing genes, but by an evolutionary process that has hierarchically shaped and optimized species genomes to function in a specific niche or environmental system. Importantly, investigations and reviews attempting to unravel the mechanistic basis of the ageing process need to differentiate clearly between the evolutionary process shaping longevity at the species level and the regulatory mechanisms that alter the individual rate of ageing.

Copyright $\odot 2012$ S. Karger AG, Basel

\section{Introduction}

By virtue of their amazing species-specific lifespan plasticity between 1 and 400 years [1,2], bivalve molluscs have become new and fascinating models in ageing research. Genetically closer to mammalian genes than established insect and worm models, long-lived bivalves are gaining interest in evolutionary and clinical ageing and senescence studies [3]. The question is: how do these animals slow senescence?

Bivalves are soft-bodied ectotherms, enclosed by calcified shell valves into which they can retract their soft tis- 
sues for protection. They feed on microalgae and detritus and occur in the sea, as well as in lentic and lotic freshwaters. Most bivalves are sessile, either endo- or epibenthic - the latter attached to hard substrates (rock surfaces or jetty bulkheads) by byssus threads or cement. Some exceptional bivalve groups are mobile and capable of autonomous bursts of swimming such as scallops (Pectinidae). Further, shallow-burrowing species do not actively swim, but retain some mobility. The prototype mobile burrowers are surf clams (Donacidae) which colonize high-energy sandy beaches and actively migrate vertically up and down taking just a few seconds to rebury. Burrowing species can, hence, also be active animals, with short lifespans ranging from just a few months to a few years.

In line with the rate-of-living - free radical theory of ageing, relatively inactive marine and freshwater bivalves can be extremely long-lived [1]. The inference that all endobenthic species should be long-lived is, however, incorrect (Donacidae), and even deep-burrowing bivalves like the temperate soft shell clam Mya arenaria live no more than 15 years whereas the longevity of Adamussium colbecki, the Antarctic swimming scallop, has been estimated at $>100$ years, albeit without proof. Although low metabolic rates and the correspondingly low mitochondrial reactive oxygen species (ROS) formation are, therefore, certainly useful to control the accumulation of cellular damage products, they cannot sufficiently explain length of life in different bivalve species. Instead, longevity will only evolve as long as it supports reproduction by optimizing the adaptation to the environment of the adult individual. Thus, the two basic prerequisites for the evolution of longevity in bivalves are the absence of reproductive senescence, i.e. sustained fertility into old age, and a near-perfect protection from predation and the physicochemical environmental hazards of the adult stage. In other words: the development of longevity depends on a hierarchy of prerequisites or constraints that enable the organism (population) to evolve long lifespans. Extreme longevity may, however, be a characteristic of only some reproductively specialized individuals in natural bivalve populations, which may also explain their scant appearance in demographic investigations.

We will discuss three general principles that support the evolution of longevity in bivalves and use long- and short-lived examples to highlight how these traits have been optimized in the long-lived champions.

\section{Principle 1: The Bivalve Shell - Protection from Predation and a Private-Protective Niche for Physicochemical Control and Self-Induced Depression of Metabolic Rate}

The bivalve shell constitutes a protective case around the soft body and confers protection from environmental attack [2]. Shells protect the animal from environmental impacts such as mechanical disturbance by waves, ice scour, and the vagaries of, for example, intertidal life. Large and tough shells protect from injury, bacterial infection, and from crab, fish and bird predation, to name but a few. Long-lived species, such as the pearl shell (Margaritifera margaritifera) and the ocean quahog (Arctica islandica) grow strong shells and are known to have low adult mortalities, as long as the populations are not exposed to fishery and bottom trawling $[4,5]$. Giant clams such as Tridacna maxima, grow large, heavy shells and although living above the sediment surface can attain an age of $>30$ years. Just as flight is one of the clues for birds to evade non-flying predators, strong shells minimize foraging pressure and enhance life expectancy in bivalves.

Shells further enable their occupants to adjust their internal environment with respect to dissolved gases, nutrients and the composition of bacterial communities in the closest proximity to their soft tissues. The shell and mantle cavity water and their blood analogue, the haemolymph, constitute layers of protection from the external to the internal. Bivalves intermittently ventilate their fluid-filled inner shell environment through, often telescopic, siphons to take up oxygen and food with inhaled water. The haemolymph contains oxygen and ions, metabolic products $\left(\mathrm{CO}_{2}\right.$ and other metabolites) and chemical signalling molecules that exert concentration-dependent effects on the animals' metabolic and shell-forming processes. The shells, thus, offer not only mechanical but also some protection from chemical fluctuations in the external environment. In other words, each bivalve creates its own inner world which can differ dramatically from the outside chemical environment (either column or interstitial water), especially with respect to the $p \mathrm{O}_{2}$. Many burrowing bivalves are oxyconformers with $\mathrm{pO}_{2}$-dependent respiration rates. It would theoretically be possible that bivalves adjust shell water $p \mathrm{O}_{2}$ through ventilation to meet metabolic requirements. Table 1 shows how median $p \mathrm{O}_{2}$ is higher in scallops and comparably lower in burrowing, more sessile clams [6].

Recent measurements with oxygen optodes implanted into the mantle cavity of $A$. islandica not only showed that 
Table 1. Median $p \mathrm{O}_{2}$ in scallops and burrowing sessile clams

\begin{tabular}{llll}
\hline Species & $\mathrm{pO}_{2}$ mean, $\mathrm{kPa}$ & Min., $\mathrm{kPa}$ & $\mathrm{Max} ., \mathrm{kPa}$ \\
\hline Aequipecten opercularis & 6.18 & 0.16 & 13.37 \\
Arctica islandica & 3.62 & 0 & 15.92 \\
Mya arenaria & 0.37 & 0 & 2.62 \\
Patella vulgata & 2.62 & 0 & 8.33 \\
Pecten maximus & 8.30 & 2.57 & 13.82 \\
\hline
\end{tabular}

this long-lived species maintains a low mantle fluid $p \mathrm{O}_{2}$ mean of $3.6 \mathrm{kPa}$ against a normoxic environment of 21 $\mathrm{kPa}$ [6] and, further, can survive many days at $0 \mathrm{kPa}$ shell water $p \mathrm{O}_{2}$ without any indication of an immediate onset of anaerobiosis [7]. Rearward analysis of the respiratory pattern of individuals also indicated a higher $p \mathrm{O}_{2}$ in the mantle fluids due to intensified ventilation $2 \mathrm{~h}$ before the onset of burrowing, presumably to generate energy (ATP) in support of the exercise [7]. We concluded that $p \mathrm{O}_{2}$ in the mantle fluids is adjusted as low as possible and as high as dictated by the individual's activity levels. Controlling environmental oxygenation low and constant is a strategy known from marine meiofaunal organisms, such as tiny ostracod crustaceans which reduce the $\mathrm{pO}_{2}$ inside mucous-lined miniature hollows by collective breathing [8]. Presumably such strategies to reduce $p \mathrm{O}_{2}$ were shared by many hypoxia-tolerant evolutionarily early species, and burrowing bivalves have adapted it by controlling mantle fluid $p \mathrm{O}_{2}$ low and protective. In so doing, they achieve low tissue $\mathrm{pO}_{2}$, which may control life-long mitochondrial ROS formation and support a longer lifespan, as seen in other hypoxia-tolerant invertebrates (e.g. nematodes) [9]. In a similar way, salinity and temperature fluctuations can, to some extent, be mitigated by closing the shell valves (salinity) and by burrowing to greater sediment depths (temperature) [2].

The ecological stress theory of ageing and hormesis predicts that critical fluctuations in physicochemical factors are major drivers of cellular ageing. Burrowing bivalves represent a consequent intermediate step between collectively-breathing meiofauna in sedimentary hollows and homeotherms which maintain a state of hormesis through interaction between different organs of the individual. In all cases, a temporarily stable environment is achieved by complexity in a confined environment (the slime hollow, the shell, the body of higher animals) which allows the organisms to establish a physiological state where energy dissipation is minimal. Reaching and pre-

Environmental Control and Control of the Environment serving this state of maximum homeostasis and metabolic stability for the longest possible time would increase overall fitness and, thereby, enhance lifespan.

\section{Principle 2: Metabolic Rate Depression and Minimized Food Uptake: Do Long-Lived Bivalves Minimize ROS Formation Rates and Maintain Higher Antioxidant Levels?}

Long-lived specialist species such as A. islandica perform bouts of intermittent burrowing and shell closure during which they enter into a phase of metabolic rate depression $[6,10]$. During these phases, individuals also stop feeding, and metabolic rates decrease to as low as $1 \%$ of control levels in well fed and ventilating specimens. This frequent transition between the active and the MRD state (also termed suspended animation) has been brought to perfection in the longest-lived bivalves and, theoretically, lowers the lifetime production of ROS. Already under normal metabolic conditions, mitochondria isolated from A. islandica tissues had lower ROS production than other bivalves [11, table 1] and excised tissues (gills and heart) were less susceptible to experimentally inflicted oxidative stress compared to shorter-lived species [12]. Our recent investigations of ROS formation, antioxidant activities, and oxidative damage in long-lived $A$. islandica populations indicated a reduction of superoxide $\mathrm{O}_{2}{ }^{-{ }^{-}}$formation between experimental normoxia and hypoxia and, further, low $\mathrm{O}_{2}{ }^{-}$formation upon reoxygenation of excised gill tissues [7] (detection with confocal microscopy using the fluorescent dye dehydroethidium). In experimental hypoxia, anoxia and MRD (burrowed individuals), the bivalves kept up their antioxidant defences (enzyme activities and glutathione levels) $[7,13]$, and antioxidant transcript levels were mostly stable in the burrowed-MRD state (catalase, glutathione peroxidase, $\mathrm{Mn}$ SOD constant, whereas $\mathrm{Cu}-\mathrm{Zn}$ SOD diminished) and under experimental hypoxia. In response to anoxia, antioxidant and stress gene transcript levels decreased altogether, as the individuals reduced protein synthesis as a consequence of metabolic shutdown [14]. It thus appears that long-lived $A$. islandica suspend the anticipatory upregulation of antioxidant/stress defence. As no oxidative damage could be observed, hypoxia reoxygenation-induced oxidative burst must be prevented by other mechanisms. Such mechanisms may involve nitric oxide (NO), which is produced by $A$. islandica haemocytes and stabilizes in the mantle fluids under hypoxic conditions [Strahl and Abele, in preparation]. Experimentally ad- 
ministered NO (produced by the NO donor spermine NONOate) reduced rapidly the respiration of bivalve gill tissue under experimental conditions and partly reduced cytochrome oxidase activity in vitro. Thus, NO may play a role in $\mathrm{MRD}$, not only by interacting with cytochromec oxidase, but also with other respiratory chain elements such as complex I with higher $\mathrm{K}_{\mathrm{m}}$, and thus lower affinity, for oxygen [15] when hypoxic conditions occur (below $10 \mathrm{kPa} p \mathrm{O}_{2}$ ). This could theoretically mitigate the reductive state of the respiratory chain to prevent the oxidative bursts in mitochondria of surfacing reoxygenating bivalves. During reoxygenation, NO becomes oxidized to nitrite which does not affect cytochrome oxidase activity [Strahl and Abele, submitted].

Interestingly, the transcriptome-based approach revealed the opposite response to anoxia exposure in Baltic Sea A. islandica from Kiel Bight. In this marginal, but stable and highly productive population, maximum lifespan (MLSP) is reduced to only 40 years. In Baltic Sea Arctica, the majority of stress genes were upregulated in response to anoxia (but not hypoxia) [14]. The Baltic Sea bivalves live in a highly fluctuating environment with fast and extreme changes in temperature, salinity and oxygen, whereas German Bight individuals experience more stable physical conditions. Adaptation to Baltic Sea conditions has led to higher physiological flexibility and stress hardening in $A$. islandica. Their adaptation to an unpredictable and fluctuating environment predisposes resident individuals to mount a more pronounced stress response at the cost of cellular maintenance and longevity. The accumulation of fluorescent age pigments, indicative of the velocity of cellular ageing, is much faster, and 30-year-old Baltic Sea individuals have a much higher lipofuscin granule density than both North Sea and Iceland A. islandica centenarians [Basova et al., unpubl. data]. We conclude that the reproductive success for sustained population density and the upkeep of stress defence in reproductive specimens are major cues for evolution in natural populations. This supports longevity as a collateral effect only if reproductive efforts have to be stretched over long time spans. Apparently this is the case in the North Atlantic Arctica populations.

Dramatic differences in the MLSP expressed by geographically separated populations of species complexes such as A. islandica in the North Atlantic and its marginal seas (the White Sea and the Baltic) are also observed in other species. Prominent examples are the geoduck (Panopea) [16] and several freshwater unionids, such as Elliptio complanata [17]. These differences can neither be explained by disparate metabolic rates (North Sea and Baltic Sea $A$. islandica have similar metabolic rates but differ five times in their MLSPs) nor by large discrepancies in antioxidant protection levels [18]. In fact, antioxidant activities and glutathione levels do not differ significantly between short- and long-lived A. islandica populations. Further, all attempts to correlate antioxidant activities with lifespan in different bivalve species have failed [1] and low molecular antioxidants such as glutathione in long-lived A. islandica are among the highest, but not above the levels measured in shorter-lived species [18]. Our recent comparison between two short-lived scallops (Argopecten ventricosus, MLSP 2 years, and Aequipecten opercularis, 10 years) and two burrowing mud clams (A. islandica, $M L S P>400$ years, and $M$. arenaria 15 years) indicated around 5-fold higher catalase activities in mantle and gill tissues of Arctica compared to the scallops and even a high discrepancy (16-fold less than A. islandica values) with $M$. arenaria in mantle tissue [19] (table 1). The high catalase activities, but not the SOD activities, decline over age in many short- and long-lived bivalves [18-21], and this is in keeping with a decline in catalase activities and GSH levels in other animal groups [22]. Therefore, if any antioxidant enzyme activity seems to correlate with ageing it would be catalase, the removal catalyst of $\mathrm{H}_{2} \mathrm{O}_{2}$ - the more persistent and less toxic pro-oxidant (compared to superoxide and $\mathrm{OH}$ ), with a larger diffusion range and important involvement in multiple chemical reactions and signalling cascades in the cells. Indeed low but persistent $\mathrm{H}_{2} \mathrm{O}_{2}$ concentrations may have a pacemaker function for ageing at the cellular level. Fine tuning and compartmentalization of these $\mathrm{H}_{2} \mathrm{O}_{2}$ signals may be involved in the regulation of cellular pathways by interacting with signalling molecules like NO (to form the highly reactive peroxynitrite), or with cellular proteins and lipids. Oxidative damage of proteins (protein carbonyls) and lipids (production of aldehydes) has been discussed as one of the cellular signals of ageing [22] that primes transcription factors [23] (FOXO or DAF-16-like proteins have yet to be identified in bivalves), cells and organs to switch between cellular maintenance (supporting longevity) and reproduction. In support of this, short-lived $A$. ventricosus (MLSP 2 years) have by far higher protein carbonyl accumulation than $>100$-year-old $A$. islandica.

\section{Principle 3: Slow Growth, Sex Change and Reproduction to Life's End}

The absence of reproductive senility, i.e. constant fertility and reproductive output independent of age, are characteristics associated with bivalve longevity $[1,2]$. 
The onset of maturation in long-lived species is often late, especially in females, and adult individuals show asymptotic, slow growth and prolonged reproduction (spawning periods) throughout the year, rather than in a distinctly timed spawning peak $[16,24]$. This strategy minimizes stress caused by exhaustive reproduction in early life and lowers oxidative damage accumulation during the extended reproductive lifespan, but this strategy may be even more sophisticated.

Many long-lived dioecious bivalves and gastropods are protandric and change sex from male to female during their lifetimes $[25,26]$. Whereas young cohorts, in which extrinsic mortality is high, usually possess a 1:1 sex ratio or are male-biased, older cohorts are often dominated by females, including female hermaphrodites, as demonstrated for the freshwater bivalves $M$. margaritifera [4] and E. complanata (lifespan 150-200 years) [27]. Female sex bias in older cohorts and protandry or hermaphroditism also occurs in long-lived marine species with $A$. islandica [24], the Northern quahog Mercenaria mercenaria, and the geoduck Panopea generosa [28 and papers cited herein] as examples. A female bias in older cohorts optimizes reproductive success, as older and larger females must invest less into somatic growth and are more reliable reproducers [25, 26]. Haag and Leann Staton [29] analysed the increase of fecundity in six long-lived freshwater mussels (Unionids, lifespan of several decades) and found that size but also age were good predictors of fecundity in all investigated species. Especially size can explain $43-88 \%$ of the variation of this trait. Although the rate of change in fecundity apparently declines in very old females, the authors reported that these aged individuals continued to produce large numbers of offspring. With many small males in the vicinity, probability rises that the energetically costly eggs will all be fertilized (especially in brooding species). The dominance of females in the older cohorts can thus either be the result of sex-specific longevity in these bivalves, or of a genetic regulation process that supports longevity in time-dependent (protandric) or real hermaphrodites. Analysing these changes of sex-specific gene expression, especially in protandric species, may thus unravel the genes important for longevity and represents a future challenge in bivalve ageing research.

Contrarily, reproductive senescence in short-lived, epibenthic and motile bivalves such as scallops and mytilids [30,31] is well documented. Short-lived bivalves, including surf clams [26], also usually display stable sex ratios of 1:1 into advanced age. As mortality from predation strikes juveniles most strongly (small size), epibenthic and shallow-burrowing species usually invest in early rapid growth, scope for activity, reproduction and stress defence at young and intermediate ages in both sexes [19, 30]. Interestingly, relatively short-lived oysters can alternate back and forth between sexes several times in their lives [25].

Evidence is accumulating for an environmental effect on the timing and intensity of sex switching in gastropods and bivalves, especially in low-density populations or those with patchy distributions and groupings. Further, removal of older (female) individuals by predators or in commercially exploited stocks induces the earlier timing of the protandric sex switch $[25,28,32]$. The effects of fisheries are most easily investigated, but other environmental impacts that affect older individuals more severely than younger ones can be anticipated to have similar effects on sex ratios. How this affects MLSP in any given population is speculative. While possibly prolonging mean population lifespan, extreme feminization may bias recruitment. The physiological transformation during protandric sex change is highly regulated and depends on different hormonal factors that support masculine gonad development in young individuals. At either a certain size/age or in response to environmental cues, these signals cease, spermatogonia are resorbed, and proliferation is induced in the premature oogonia [25]. First evidence indicates that contaminants which act as endocrine disrupters can reduce oestrogen sensitivity in bivalve gonads and cause a masculinization in polluted populations $[33,34]$. This can affect local extinctions and should receive increased attention in future research.

Female bias and, especially, a protandric life history may thus be the ecological mechanism underlying extreme longevity in some freshwater and marine bivalves. During the early male life stage, individuals invest in growth, stress defence, and energetically less consuming masculine reproduction before switching to the later female stage which might then be better preconditioned for survival. Gribben and Creese [28] suggested that this gives the protandric female an advantage over its strictly dioecious relatives. The few outstandingly old specimens in long-lived bivalve populations could, thus, theoretically, be the protandric individuals, but this hypothesis will need to be supported by closer examination. In such a case, sexual transformation may prime an individual to express longevity-supporting genes by eliciting pathways that yet have to be elucidated in bivalves. In view of the peculiar lifestyle of $A$. islandica, its adaptation to low oxygen environments and its extremely energy-saving behaviours and periodic transition to self-induced anaero- 
biosis, energy-saving pathways such as either the insulin/ insulin receptor pathway or autophagic pathways are strong candidates to start the search for mechanisms of life extension. Investigations of sex- and age-related differential gene expression in species with no a priori genetic sex determination may, thus, be a promising strategy to unravel the mysteries of female longevity in higher animals, including human beings.

\section{Acknowledgements}

We are grateful for discussions with Professor Brian Morton (Natural History Museum, London) and Professor Volodya Lushchak (Precarpatian National University, Ivano-Frankivsk, Ukraine). Much of our own scientific work presented here as a viewpoint was supported by DFG grant No. AB124/10-1 and by the AWI and the IKMB.

\section{References}

1 Philipp EER, Abele D: Masters of longevity? Lessons from long-lived bivalves - review. Gerontology 2010;56:55-65.

$\checkmark 2$ Ridgway ID, Richardson CA, Austad SN: Maximum shell size, growth rate, and maturation age correlate with longevity in bivalve molluscs. J Gerontol A Biol Sci Med Sci 2010; 66A:183-190.

3 Austad SN: Is there a role for new invertebrate models for aging research? J Geront A Biol Sci Med Sci 2009;64A:192-194.

4 Bauer G: Reproductive strategy of the freshwater pearl mussel Margaritifera margaritifera. J Anim Ecol 1987;56:691-704.

5 Witbaard R, Bergman MJN: The distribution and population structure of the bivalve Arctica islandica L. in the North Sea: what possible factors are involved? J Sea Res 2003 50:11-25.

6 Abele D, Kruppe M, Philipp EER, Brey T: Mantle cavity water oxygen partial pressure $\left(\mathrm{PO}_{2}\right)$ in marine molluscs aligns with lifestyle. Can J Fish Aquat Sci 2010;67:977-986.

-7 Strahl J, Brey T, Philipp EER, Thorarinsdottir G, Fischer N, Wessels W, Abele D: Physiological responses to self-induced burrowing and metabolic rate depression in the ocean quahog Arctica islandica. J Exp Biol 2011;214:4221-4231.

8 Corbari L, Carbonel P, Massabuau J-C: The early life history of tissue oxygenation in crustaceans: the strategy of the myodocopid ostracod Cylindroleberis mariae. J Exp Biol 2005;208:661-670.

9 Lee SS, Lee RY, Fraser AG, Kamath RS, Ahringer J, Ruvkun G: A systematic RNAi screen identifies a critical role for mitochondria in $C$. elegans longevity. Nat Genet 2003;33:40-48.

10 Taylor AC: Burrowing behaviour and anaerobiosis in the bivalve Arctica islandica $\mathrm{L}$. J Marine Biol Assoc UK 1976;56:95-109.

-11 Buttemer WA, Abele D, Costantini D: From bivalves to birds: oxidative stress and longevity. Funct Ecol 2010;24:971-983.

-12 Ungvari Z, Ridgway I, Philipp EER, Campbell CM, McQuary P, Chow T, Coelho M, Didier ES, Gelino S, Holmbeck MA, Kim I, Levy E, Sosnowska D, Sonntag WE, Austad $\mathrm{SN}$, Csiszar A: Extreme longevity is associated with increased resistance to oxidative stress in Arctica islandica, the longest-living non-colonial animal. J Gerontol A Biol Sci Med Sci 2011;66A:741-750.
Strahl J, Dringen R, Schmidt MM, Hardenberg S, Abele D: Metabolic and physiological responses in tissues of the long-lived bivalve Arctica islandica to oxygen deficiency. Comp Biochem Physiol 2011;158A:513-519.

14 Philipp E, Wessels W, Gruber H, Strahl J, Wagner A, Ernst IMA, Rimbach G, Kraemer L, Schreiber S, Abele D, Rosenstiel P: Gene expression and physiological changes of different populations of the long-lived bivalve Arctica islandica under low oxygen conditions. PLoS One 2012;7:e44621.

15 Barja G: Mitochondrial oxygen consumption and reactive oxygen species production are independently modulated: implications for aging studies. Rejuvenation Res 2007;10: 215-224.

16 Breen PA, Gabriel C, Tyson T: Preliminary estimates of age, mortality, growth, and reproduction in the hiatellid clam Panopea zelandica in New Zealand. NZ J Mar Freshwater Res 1991;25:231-237.

-17 Anthony JL, Kesler DH, Downing WL, Downing JA: Length-specific growth rates in freshwater mussels (Bivalvia: Unionidae): extreme longevity or generalized growth cessation? Freshwater Biol 2001;46:1349-1359.

18 Basova L, Begum S, Strahl J, Sukhotin A, Brey T, Philipp E, Abele D: Age-dependent patterns of antioxidants in Arctica islandica from six regionally separate populations with different life spans. Aquat Biol 2012;14: 141-152.

-19 Guerra C, Zenteno-Savín T, Maeda-Martínez AN, Philipp EER, Abele D: Changes in oxidative stress parameters in relation to age, growth and reproduction in the short-lived catarina scallop, Argopecten ventricosus, reared in its natural environment. Comp Biochem Physiol A Mol Integr Physiol 2012; 162:421-430.

20 Philipp E, Brey T, Heilmayer O, Abele D, Pörtner HO: Physiological ageing in a polar and a temperate swimming scallop. Mar Ecol Prog Ser 2006;307:187-198.

21 Ivanina AV, Sokolova IM, Sukhotin AA: Oxidative stress and expression of chaperones in aging mollusks. Comp Biochem Physiol B Biochem Molecular Biol 2008;150:53.

22 Sohal RS, Allen RG: Oxidative stress as a causal factor in differentiation and aging: a unifying hypothesis. Exp Gerontol 1990;25: 499-522.
23 Kenyon CJ: The genetics of ageing. Nature 2010;464:504-512.

24 Thorarinsdottir G: Annual gametogenic cycle in the ocean quahog Arctica islandica from north-western Iceland. J Mar Biol Assoc UK 2000;80:661-666.

25 Wright WG: Sex change in the mollusca. Trends Ecol Evol 1988;3:137-140.

26 Morton B: Do the bivalvia demonstrate environment-specific sexual strategies? A HongKong model. J Zool 1991;223:131-142.

27 Downing JA, Amyot J-P, Perusse M, Rochon Y: Visceral sex, hermaphroditism, and protandry in a population of the freshwater bivalve Elliptio complanata. J North Am Bentholog Soc 1989;8:92-99.

28 Gribben PE, Creese RG: Protandry in the New Zealand geoduck, Panopea zelandica (Mollusca, Bivalvia). Invertebr Reprod Dev 2003;44:119-129.

29 Haag WR, Leann Staton J: Variation in fecundity and other reproductive traits in freshwater mussels. Freshwater Biol 2003;48: 2118-2130.

30 Thompson RJ: Production, reproductive effort, reproductive value and reproductive cost in a population of the blue mussel Mytilus edulis from a subarctic environment. Mar Ecol Prog Ser 1984;16:249-257.

31 Bricelj VM, Krause MK: Resource allocation and population genetics of the bay scallop, Argopecten irradians irradians: effects of age and allozyme heterozygosity on reproductive output. Mar Biol 1992;113:253-261.

32 Romo Piñera AK, Patricia Ceballos-Vázquez B, García-Domínguez F, Arellano-Martínez M: Unusual high frequency of hermaphroditism in the gonochoric bivalve Megapitaria squalida (Sowerby, 1835) (Veneridae). J Shellfish Res 2009;28:785-789.

33 Gagné F, Blaise C, Pellerin J, Pelletier E, Douville M, Gauthier-Clerc S, Viglino L: Sex alteration in soft-shell clams (Mya arenaria) in an intertidal zone of the Saint Lawrence River (Quebec, Canada). Comp Biochem Physiol C Toxicol Pharmacol 2003;134:189-198.

34 Oehlmann J, Di Benedetto P, Tillmann M, Duft M, Oetken M, Schulte-Oehlmann U: Endocrine disruption in prosobranch molluscs: evidence and ecological relevance. Ecotoxicology 2007;16:29-43. 